Visual Fields.

Left. White.-Large absolute central scotoma but no peripheral constriction. (Fig. 3.)

Colour.-No perception of red or green throughout the field.

Right. $\left.\begin{array}{l}\text { White } \\ \text { Colour }\end{array}\right\}$ Normal.

Wassermann Reaction.-Negative. Urine.-Negative. Teeth.$\mathrm{X}$-ray is negative. Ear, nose and throat.- "No evidence of infection." X-ray orbit.- " Slight increased density of left as compared with right orbit." Optic foramen.- " No apparent abnormality." Skull._- " No abnormality. In the antero-posterior view the greater density of the left orbit is also shown.

General Examination.-Negative.

The patient was seen by all the members of the staff, and although they were not unanimous as to the diagnosis, yet several of them considered that, in view of her facial naevus and the X-ray report, she had a naevus of her choroidal and orbital vessels causing slight back pressure which was exhibited in her sclera by engorgement of the vessels and in the retina by oedema. They were unanimous that no further treatment was indicated.

I have to thank Mr. Duke-Elder for permission to publish this case.

\title{
ATYPICAL COLOBOMA AND VASCULAR ANOMALY
}

BY

\section{Leslie Buchanan}

GLASGOW

The paper published in The British Jolrnal of Ophthalmology, December, 1929, p. 608, by Drs. Ida Mann and Jas. A. Ross has been of great interest to me as it recalled to my mind a somewhat similar case which I saw at the Glasgow Eye Infirmary in 1904.

I made a rough sketch of the condition at the time and some months later sent the sketch to $\mathrm{Mr}$. Treacher Collins for his opinion. Mr. Collins considered the sketch as probably representing the clinical appearance which one would have seen in his case of microphthalmos shown in section in plate IV, Trans. Ophthal. Soc. U.K., Vol. XIII.

I kept the sketch beside me hoping to get something like it some day to publish with it, but nothing just similar has been seen until I read the paper in this journal last month. The case of which I 


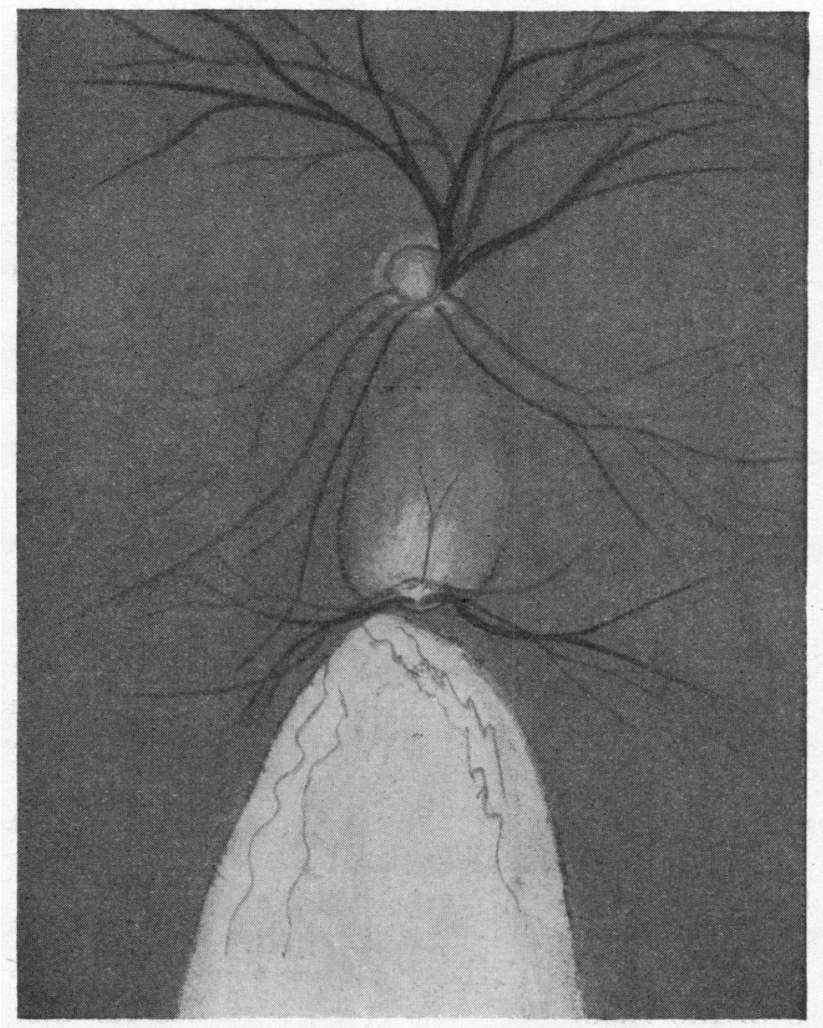

enclose a sketch was that of a young man who came to see if his right eye could be assisted by the use of spectacles. He had fairly good vision in this eye, $6 / 12$ when corrected. There was no outward evidence of malformation of the eye or other parts. The left eye was quite normal.

The appearance in the fundus was that of a large coloboma of the choroid with a small band of normal appearance above it. Above the normal band was what appeared to be a small optic nerve entrance with a large ectasia upwards. Blood vessels extended in two regular groups, one to the right, one to the left, each containing an artery and a vein. A small vessel extended up along the ectasia and branched.

About a disc's breadth above the upper extremity of the ectasia there was another optic nerve entrance of moderately normal appearance. The principal departure from the normal was the 
distribution of the blood vessels. The veins and arteries at the lower part were small compared with those at the upper part. The vessels all seemed to come more from the nasal than the central part of the nerve.

There was no other congenital abnormality in the eye and there was no spot of choroidal or other disease at any part of the fundus.

I formed the impression, at the time, that the condition might be due to, or connected with, an unusually placed division of the central retinal artery and vein coincident with, perhaps connected with, the late closure of the choroidal cleft.

\section{ANNOTATIONS}

\section{Ophthalmic Benefits*}

Ophthalmic surgeons have taken comparatively little interest individually in ophthalmic benefits and in the various administrative schemes which have been proposed. Now that the valuation period of the Approved Societies is rapidly approaching it is more than probable that there will be an increase in number of the societies who will give this additional benefit. It originally arose as the result of some of the societies wishing to provide their members with glasses to correct errors of refraction, and when first instituted by them was called an optical benefit and was administered under the clause in the Insurance Act which provides for instruments. The patients were for the most part sent to sight-testing opticians who provided them with glasses. Mainly as the result of a repre-

\footnotetext{
* The following are the Ophthalmic bodies interested.

Council of British Ophthalmologists.

Body constituted by a meeting of British ophthalmologists who hold an annual meeting and elect a Council.

The Council is composed of Presidents and Past Presidents of the Ophthalmological Society of the United Kingdom, the Section of Ophthalmology of the Royal Society of Medicine, and the Oxford Ophthalmological Congress, together with elected representatives from these bodies.

The Ophthalmic Committee of the British Medical Association appointed by the Council of the B.M.A., and composed of ophthalmic surgeons with affiliated members from the other sections of the B.M.A., together with three members of the C.B.O. (a recent concession).

Association of Dispensing Opticians.

A recently formed Society of Dispensing Opticians for their members' welfare.

National Ophthalmic Treatment Board. (N.O.T.B.) Consists of three representatives from the B.M.A., and three representatives from the Society of Dispensing Opticians together with the secretary of the B.M.A.,. and the secretaries of the Dispensing Opticians.

? Provision made for Insurance Societies.
} 